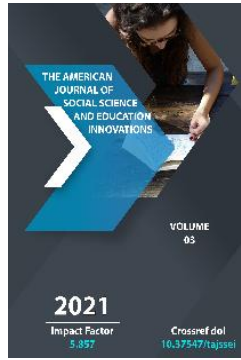

\title{
In The Karakalpak Language, The Terms For A Dish Made From Flour Patch Dough
}

\author{
Esbergenova Rysgul Begdullaevna \\ Trainee-Researcher, Karakalpak State University, Uzbekistan
}

Journal Website:

https://theamericanjou

rnals.com/index.php/ta

jssei

Copyright: Original content from this work may be used under the terms of the creative commons attributes 4.0 licence.

\section{ABSTRACT}

Porridge is a thick food made from flour or cereals. There are several types of this food, depending on the product: Let's try to make it from flour, katybylamyk uzbentai - a kind of boiled corn flour boiled in water, flour porridge - a kind of porridge made from millet, shalma karma - a kind of sorghum flour soaked in fish soup, thick oatmeal with flour and milk, oatmeal, porridge, flour from various cereals, oatmeal.

\section{KEYWORDS}

Varied Dishes, Bakery Products, Bread, Baursak.

\section{INTRODUCTION}

Karakalpaks have many and varied dishes made from flour products.

Flour is a raw food that can be obtained by grinding in a grain mill or baking a variety of bakery products. You can learn how to make flour and dough into several types:

1) Names of food made from flour

2) Terms of bakery products
3) Terms of food to be prepared from dough

1) There are not many dishes made from flour. Nowadays, almost no flour is made from flour alone. One of the foods you should avoid:

Terms of bakery products. Bread has long been known as a delicacy. Bread products are made 
from flour by adding yeast, baking soda and salt to the dough.

A soft mixture that is formed by mixing the dough with water or milk.

Breads are divided into milk, fat, onion, and meat. At the same time, bakery products are made with or without yeast.

Yeast is something that is leavened from the dough to be baked.

Bread, baursak, flatbread for sourdough bread products//jayman // sozban // possiq, katlama, zagara, loaf.

Baursak is a type of bread that is made of thick dough, cut into rounds or four-horned and baked in oil. There are several types of baursaks: shea baursak, kudagai baursak. Shea baursak is a small type of baursak. It is usually cooked for a wedding. Kudagai baursak is larger than Shii baursak, which is also baked at weddings.

A flatbread is a thin round loaf of bread baked in butter. We can see some differences in the name of the cake. For example: in Takhtakopir and Karaozek districts it is called shelpek, in Khojeli and Shomanai districts it is called zhayman. In the Kubla dialect, it is called possyk. Representatives of Yellikkala district call the cake a possyk. However, in her dissertation, Haidarova learned to bake and bake separately. He points out that tortillas are a type of bread that is fried in oil. This applies to two types of food: 1 . The type of food that is cooked thinly is understood, and Karakalpaks call the food that is prepared in the same way as tortillas. 2. This is a type of bread in which the dough is spread thinly and baked in a pan or hot pot without fat. When it is cooked, it is folded in layers and rubbed hard between the cakes. This is called a hard cake $[3,61]$. According to some sources, the dough is called sozban. In the book by F. Abdullayev "Khorezm
Shevalari" it is called possyk-donchik (meatless somsa) $[1,112]$. So, as you can see, there are two types of cakes: one type is fried in oil, and the other is baked in a non-fat frying pan.

The above are the types of bread fried in oil. There are also types of bread that can be baked in the oven or in the oven without frying in oil. They are:

A quarter is a loaf of bread baked in a tandoor in a circle. There are several types of shorek: kümeş // külkömesh, gümpey nan, gülşe.

Silver // ash is a loaf of bread that is baked in a pan or between unextinguished ashes. It is located in the pit and is connected with the topsoil and the suffix - (e) sh, which means "burial" [3,29].

N.M. Ikramova writes that silver was eaten by nomads made by shepherds in the deserts [4,19-21].

Mushroom bread is a very crunchy type of bread.

Gulshe is a type of shorek that is frozen in a pot or covered with a tandoor and baked in a pot. This bread, along with a loaf of bread, was used to shrink the bread and cover the children's heads.

A layer is a type of bread that is frozen in a pan or tandoor with oil in between. In some areas, bread baked in oil is called layering, and baking in the tandoor is called flat.

Pot mass // cardboard is a type of bread covered in a pot and frozen in a pot.

A type of bread in which a small amount of oil is added to a pan and then the finished dough is placed is called a pan bread. The dough bends like a quarter and is a little thicker.

Bukhanka // loaf of bread is a type of fourcornered bread made of soft, crunchy, high- 
quality bread, which is baked in the desired mold for iron.

Goshli bread is a loaf of bread that is baked in a pan or oven, with the meat in the middle of the dough. More is being prepared in the Khojeli district.

The people of Karakalpakstan have long used wheat and corn flour in the preparation of bakery products, and made corn flour.

Zagara is a bread made by adding gesher or pumpkin to the flour of jueri, millet or shigin, soaking it in hot water, adding yeast and mixing it with wheat flour in a tandoor. It is slightly smaller and thicker than a loaf of bread. Zagara is still loved and eaten as a tasty and nutritious food. It is mostly prepared during the winter and Nauryz holidays.

Among the bakery products there are also types of bread that are prepared without yeast. They are flat, pancakes and lamb

Flat // flat bread is a thin loaf of bread that can be baked in a pan without leavening. Flat is an Arabic word meaning "unleavened, unleavened."

There are different types of flats: onion flat, meat flat.

Folding flat is a type of bread that is heated in a frying pan with butter and white oil, spread with a mixture of fried onions, spread on a thin layer of dough and rolled and folded in the oven or baked in the oven.

A flat apartment is a loaf of bread that is spread thinly in the oven without putting anything in between. This type of flatbread is often used to make bread soup or toast.

Aksaulak is a type of bread that makes the dough thin and unleavened. She puts a few things in her work and prepares a dish called shawarma.
Pancakes - soft bread made of flour with liquid dough and baked in oil. Nowadays, it is also prepared by adding milk and buttermilk to the work.

In addition, bakery products include baked bread // baked bread, cardboard, tandoor bread, market bread, homemade bread, pan bread, casserole bread, buns, puff pastry, onion bread, meatloaf, sourdough bread, as well as for ceremonies. There are bread, charity bread, wedding bread.

3) Names of dishes made from dough. Food names that fall into this group can be divided into: 1) liquid food names made from dough and 2) thick food names made from dough.

1) The names of liquid dishes made from dough. Such dishes include kespas // una // unasy // unashi, lagman, pelmen, uzben, zhulmay, small gurtik, sykpan.

Kespas - you can fry meat, onions, geshir, potatoes, pour water and knead the dough made of wheat flour. Representatives of Shymbay, Takhtakopir, Karaozek, Khojeli districts call this type of food kespas // unasy // unashi // uzben. There are several types of this dish: milk thistle, curd thistle, egg thistle, chicken thistle. Nowadays, however, chicken is rarely cooked, except for the carcass.

Laghman is a kind of noodles that are cooked separately by adding fried meat. This dish is prepared in two forms: soup lagman, fried lagman.

Pelmen is a dish that is cooked by placing minced meat between the dough.

In addition, there are some dishes that are now being forgotten: do not pluck, do not squeeze.

Zhulmay is a liquid food that is not cut into wheat dough, but pulled into small pieces in a pot and stuffed with kefir and torak. 
Uzben is a kind of yoghurt that is used to cut the dough into pieces.

Sykpan is a liquid dish in which the dough is soaked in flour and squeezed by hand through the fingers. Instead of squeezing it with their fingers, the townspeople squeeze the dough into a hole and make it into a long shape.

2) The names of the dishes from which the dough is prepared. The following can be specified for thick dishes: gurtik, maisalmak, maisalman, naryn // par tuurama, tuurama, uumash, pigudi, aksaulak, manty, kanym, berek, etc.

3) Gurtik is a dish made from wheat or corn flour. Meat, onions, geshir, potatoes are boiled in water. Then it is called biydai gurtik, which is made of wheat flour by bending, spreading and crushing into four horns. The dough is placed on a tray, and the soup is poured into a cup and drunk. The fact that onions, geshir, potatoes, etc. are fried without water, and water is added to the boiled soup is called gurtik.

4) Corn on the cob-a dish that is prepared like a soup of wheat gourd. It is a dish in which corn flour is soaked in boiling water, then wheat flour is added to it, the dough is cut off by hand, rolled into a flat shape with the help of fingers and put in boiling soup. On top of the above-mentioned gurtik (wheat, zhuyeri gurtik), the last thing is put in the soup, that is, the killed onion.

5) Salt is a greasy soup with chopped onions to pour over the gourd or turmeric. Food to prepare a tasty meal.

6) Tuurama is a food made of meat and gurtik. Jueri tuarama is a dish made from jueri flour mixed with gurtik. Wheat flour is a food made from wheat flour mixed with wheat flour.

7) Aksaulak is a type of bread that is made without leavening the dough into very thin layers. Aksaulak is one of the national dishes of Karakalpakstan: melon aksaulak melon is boiled completely, mixed with yogurt, cut into pieces and fried in butter. The soup is hung on the meat, as if hung on a skewer.

8) Maisalmak // maisalman - hangs a pumpkin, puts a gourd on it and pours oil on it.

9) Borek is a dish that is cooked in water and oil with the addition of butter, meat, potatoes, etc. to the dough.

10) Uuz borik is a dish in which Uuz milk is added to the dough and cooked in water.

11) Buttermilk - a mixture of buttermilk and butter between the dough, boiled in boiling water and poured yogurt on top.

Naryn // par tuurama - the dough is spread out like a skewer, greased and returned, and the manti is steamed in a pot. The soup is prepared in the same way as the broth. Cooked dough and meat, potatoes, geshir are finely chopped and mixed. Salt is also prepared for this meal and it is added to the food. In some districts this dish is called naryn, in others it is called par tuurama (Takhtakopir). The reason it is called steam is probably because the steam is steamed and cooked.

Manti is a dish in which the minced meat and onion are folded into a dough and steamed in a pot in a pot. Depending on the ingredients, there are different types of mantis: belly manty, meat manty, cold manty, potato manty.

Kanym is a dish in which the dough is spread out thinly, stuffed and wrapped in the dough and steamed in a pot.

Uumash // Uuman is a dish in which freshly baked bread is cut into small pieces and smeared with butter by hand if it is not soaked in soup oil. Currently, this dish is not prepared at home, it is one of the most sought-after dishes. 
Somsa and confectionery include soms, pies // ants, mushrooms, cakes, pies, cookies, gingerbread, etc. included.

Somsa is a dish that is made by spreading meat, zucchini, potatoes in the dough and baking in the oven. Somsa is prepared in two different ways. Usually in a tandoor made of unleavened dough, layered somsa made from unleavened opium dough is baked in the oven. There are tandoor somsa, bazaar somsa, house somsa, oven somsa, cold somsa, potato somsa, green somsa, wall somsa, three-horned, four-horned, drip, round, braided.

Green somsa is a mixture of freshly grown alfalfa and horseradish mixed with onions into fermented or unleavened dough.

Gumme - If you put minced meat in unleavened dough, bend it in a three-cornered form and cook it in a tandoor or in a pan. Gumme was originally a type of bread (kumme) that was prepared by burying it in the ground at the bottom of the fire, if not in the ashes, and later in the form of a kumme. Depending on the material (mass) used in its work, it is called goshli gomme, kabakli gumme, kokme gumme, geshir gumme.

Roll out the dough thinly, cut it into fourcornered or round shapes, add meat, potatoes and pumpkin to the dough and fry it finely. Depending on what stuff is put in it, potatoes are called scab, pumpkin scab, green scab.

The current name, in our opinion, is called a pie. Nowadays, the meaty type of pie is mostly prepared at weddings and holidays, on Eid days.

Belyashi is a dish made of sourdough dough, which is stuffed with minced meat, meat, onions, folded and fried in oil.Pie is a bread, a dish baked in the oven with meat, fish, cabbage, jam, etc. between the dough.
Biscuits are confectionery products made of delicious dough, baked in small rounds, fourcornered and other forms.

Gingerbread is a confectionery product that is baked with vegetable oil, pal, sugar.

Bun is a tasty dish that is fermented and mixed with milk, butter, salt, sugar, yeast and butter.

Pizza - knead the dough by adding mayonnaise, mayonnaise, sour cream. Tomatoes, cheeses, onions, sausages are peeled and spread on them. It is then baked in the oven. This Italian national dish first appeared in Naples in 1522, when tomatoes began to be imported to Europe. He came to our country in the early 1990s. First of all, this food was the food of the poor.

Hot dog is a dish with sausage or ketchup between soft breads.

Preparation of the dish: the dough is mixed with milk, butter, salt, sugar, yeast, butter, and the minced meat needs meat, onion, butter, salt, pepper, soy sauce, tomato paste, water. It is topped with sausage, grated cheese, sour cream and herbs.

Hamburger - a dough with milk, margarine, a little sugar, yeast, salt, buttermilk. The meat is stuffed with onions and the cutlet is smoked. Then cut in the middle of the bun, put the mixture of ketchup and mayonnaise on one side, that is, the sauce, and then cover the other side with, lettuce, tomatoes and cucumbers.

This dish is known all over the world. The origins of American cuisine go back to people from Hamburg. German chefs enriched the food with their new ideas and made it convenient to eat on the go. Slave, it is now known as American and German food.

Lavash // shawarma - this dish, known worldwide as thin bread, is widely sought after 
in Armenia, Iran, Turkey, Kazakhstan and Azerbaijan. Baked in a tandoor at 300-350 degrees on the basis of real lavash. Today, lavash is used to make shaurma, a Turkish national dish. Meat dish wrapped in thin dough. The lavash is preceded by chicken breast, cucumbers, tomatoes, pickles, mayonnaise, ketchup and dough.

\section{CONCLUSION}

In this article, we have included the terms of food that are currently being made from flour and dough and are being aspired to, as well as those that cannot be prepared at home. It is possible to make a dish out of it. In the culinary section, along with the old food names, there are many new food names. This indicates that the vocabulary of the food section is very rich.

\section{REFERENCES}

1. Abdullaev F. Khorezm dialects.Tashkent, 1981.

2. Explanatory dictionary of the language of Alisher Navoi's works.Tashkent: Fan, 1983.

3. Khudayarova M. Linguistic analysis of food names in Uzbek language. Dissertation... Candidate of Philology. Tashkent, 2010.

4. Ikramova NM Uzbek culinary vocabulary. Tashkent, "Fan", 1989. 